\title{
Dendritic Cell Generation AND CD4+CD25 HighFOXP3+ Regulatory T Cells in Human Head and Neck Carcinoma during RADIO-CHEMOTHERAPY
}

\author{
P. J. Schuler ${ }^{1,2}$, V. Börger ${ }^{3}$, E. Bölke ${ }^{4}$, D. Habermehl ${ }^{5}$, C. Matuschek ${ }^{4}$, C. A. Wild ${ }^{1}$, J. Greve ${ }^{1}$, M. Bas 6 , \\ B. Schilling ${ }^{2}$, C. Bergmann ${ }^{1}$, S. Trellakis ${ }^{1}$, W. Budach ${ }^{4}$, T. Gauler ${ }^{7}$, S. Brandau ${ }^{1}$, S. Lang ${ }^{1}$, T. L. Whiteside ${ }^{2}$, \\ R. V. Sorg ${ }^{3}$, T. K. Hoffmann ${ }^{1}$ \\ ${ }^{1}$ Hals-Nasen-Ohrenklinik, Universität Duisburg-Essen, Essen, Germany \\ ${ }^{2}$ Hillman Cancer Center, University of Pittsburgh, Pittsburgh, PA, USA \\ ${ }^{3}$ Institut für Transplantationsdiagnostik und Zelltherapeutika, ${ }^{4}$ Klinik für Strahlentherapie und Radioonkologie, \\ Heinrich-Heine-Universität, Düsseldorf, Germany \\ ${ }^{5}$ Klinik für Radioonkologie, Universitätsklinikum Heidelberg, Heidelberg, Germany \\ ${ }^{6}$ Hals-Nasen-Ohrenklinik, Technische Universität München, Klinikum Rechts der Isar, München, Germany \\ ${ }^{7}$ Klinik für Innere Medizin, Westdeutsches Tumorzentrum, Universität Duisburg-Essen, Essen, Germany
}

\begin{abstract}
Background: Regulatory $\mathrm{T}$ cells (Treg) and dendritic cells (DC) play an important role in tumor immunity and immune escape. However, their interplay and the effects of anti-cancer therapy on the human immune system are largely unknown.

Methods: For DC generation, CD $14^{+}$monocytes were enriched by immunomagnetic selection from peripheral blood of advanced head and neck squamous cell carcinoma (HNSCC) patients and differentiated into immature DC using GM-SCF and IL-4. DC maturation was induced by addition of TNF $\alpha$. The frequency of $\mathrm{CD}^{+}{ }^{+} \mathrm{CD} 25^{\text {high }} \mathrm{FOXP} 3^{+}$Treg in HNSCC patients was analyzed before and after radio-chemotherapy (RCT) by four-color flow cytometry.

Results: In HNSCC patients, the frequency of Treg $(0.33 \pm 0.06 \%)$ was significantly $(\mathrm{p}=0.001)$ increased compared to healthy controls $(0.11 \pm 0.02 \%)$, whereas RCT had variable effects on the Treg frequency inducing its increase in some patients and decrease in others. After six days in culture, monocytes of all patients had differentiated into immature DC. However, DC maturation indicated by CD83 up-regulation (70.7 \pm $5.5 \%$ ) was successful only in a subgroup of patients and correlated well with lower frequencies of peripheral blood Treg in those patients.

Conclusion: The frequency of regulatory $\mathrm{T}$ cells is elevated in HNSCC patients and may be modulated by RCT. Monocyte-derived DC in HNSCC patients show a maturation deficiency ex vivo. Those preliminary data may have an impact on multimodality clinical trials integrating cellular immune modulation in patients with advanced HNSCC.
\end{abstract}

Key words: head and neck cancer, dendritic cell, vaccination, regulatory $\mathrm{T}$ cell, chemotherapy

Abbreviations:
5-FU 5-fluorouracil
DC $\quad$ Dendritic cells

FOXP3 Forkhead box P3

GM-CSF Granulocyte macrophage colony-stimulating factor

HNSCC Head and neck squamous cell cancer

PBMC Peripheral blood mononuclear cells

RCT Radio-chemotherapy

TGF $\beta$ Transforming growth factor beta

TNF $\alpha$ Tumor necrosis factor alpha

Treg Regulatory T cells

\section{INTRODUCTION}

Radical surgery and various radio-chemotherapy (RCT) regimens represent the current therapy standards for patients with head and neck squamous cell cancer (HNSCC). However, local recurrence and distant metastasis are still the major limiting factors for improving survival rates [1]. Aside from anti-EGFR antibody therapy and targeted therapy with tyrosine kinase inhibitors, newer therapeutic approaches have been focused on dendritic cell (DC)-based immunotherapy [2]. DC are unique antigen-presenting cells characterized by their potent T-cell stimulatory activity and therefore, they are preferentially utilized in cancer vaccines [3]. Immature DC capture antigens in peripheral tissues and migrate to secondary lymphoid organs after danger signal-induced maturation. There, DC present the captured antigens to specific $\mathrm{T}$ cells. For cancer vaccination, DC are loaded with specific tumor antigen or mRNA and administered to cancer patients in hope of stimulating an anti-tumor T-cell response [4]. A number of human vaccination studies utilizing DC have been recently published for various tumor entities, however, DC-based vaccinations for therapy of human HNSCC are rare [5].

The production of DC-based vaccines requires techniques for a large-scale ex vivo generation of clinical-grade DC, and several methods for DC generation have been established [3]. DC can be directly isolated from the peripheral blood, which may be hampered by 
the low number and functional abnormalities of DC in cancer patients [6]. Currently, DC culture for therapy utilizes monocytes separated from leukapheresis products [7]. For this purpose, in patients with cancer, monocytes have to be collected before RCT as their number drops rapidly after RCT. Whether HNSCC patients at this disease stage have functionally normal monocytes which can be used to generate DC vaccines is currently unknown.

To date, DC-based vaccines for cancer have not yet fulfilled their promise, as clinical benefits are only rarely reported in therapeutic vaccination trials, such as in prostate cancer [8]. This lack of clinical benefits might be partly due to the strong immunosuppressive influence of regulatory $\mathrm{T}$ cells (Treg) in cancer patients with advanced malignancies.

$\mathrm{CD} 4{ }^{+} \mathrm{CD} 25^{\text {high }} \mathrm{FOXP} 3{ }^{+}$Treg play an important role in various human diseases including the development of allergy [9], host-versus-graft-reaction in transplantation [10], and autoimmune diseases [11]. All are associated with a decrease in Treg numbers. In contrast, in cancer patients, Treg are frequently elevated and can inhibit T-cells, DC, natural killer T-cells and even Bcells, thereby probably contributing to tumor immune escape [12]. The potential influence of RCT on Treg has been addressed in several recent studies. In breast cancer, $\mathrm{FOXP}^{+}$cells infiltrating the tumor were decreased in frequency after neoadjuvant chemotherapy, and a reduced Treg infiltration correlated with improved responses [13]. Also in breast cancer, trastuzumab therapy in combination with chemotherapy resulted in a decrease of Treg in peripheral blood [14]. In end-stage cancer patients with various tumor types, a low dose of cyclosphosphamide caused a selective depletion of Treg in peripheral blood [15]. For HNSCC, a study by Strauss et al. showed that oncologic therapy induced a significant increase in the frequency and suppressor function of Treg in the peripheral circulation. Surprisingly, HNSCC patients had a higher frequency of Treg after successful therapy compared to patients with active untreated disease [16].

The present study focuses on DC generation and the alteration of $\mathrm{CD}^{+}{ }^{+} \mathrm{CD} 25^{\text {high }} \mathrm{FOXP} 3{ }^{+}$Treg during
RCT in HNSCC patients. Understanding the frequency and function of Treg and DC is necessary to effectively orchestrate the various regimens of surgery, RCT and anti-cancer immune therapy.

\section{Material AND Methods}

\section{Study design}

Patients of all age groups with the diagnosis of HNSCC (T1-4) donated blood for the generation of DC (mean age: 63.1yrs, 0 female, 9 male) and Treg quantification (mean age: $58.8 \mathrm{yrs}, 2$ female, 11 male) after informed consent. Experiments were approved by the local ethics committee. Two patients suffered from recurrent tumor disease, and all patients received primary or adjuvant RCT with curative intent (Table 1). DC generation was performed prior to RCT, and the frequency of Treg was determined before as well as one week $(6.8 \pm 2$ days $)$ after chemotherapy. Three different protocols of chemotherapy were distinguished: (a) Single dose of cisplatin $(\mathrm{n}=3)$, (b) one course of 5fluorouracil and cisplatin \pm cetuximab $(n=4)$, and (c) one course of mitomycin $C$ and cisplatin $(n=6)$. The control group consisted of 10 healthy volunteers.

\section{Generation of dendritic cells}

DC were generated following a protocol adapted from Zhou et al. [17, 18]. CD14 ${ }^{+}$monocytes were immunoselected from peripheral blood mononuclear cells (PBMC) using LS separation columns on a VarioMACS (Miltenyi Biotec, Bergisch Gladbach, Germany). Enriched $\mathrm{CD}_{14}{ }^{+}$monocytes were cultured in 24-well plates (Greiner, Nürtingen, Germany) at $1 \times 10^{6}$ cells $/ \mathrm{mL}$ and $2 \mathrm{~mL} /$ well of serum-free CellGroDC medium (Cellgenix, Freiburg, Germany) supplemented with 1,000 U/mL GM-CSF (Leukine, Berlex, Richmond, CA) and 1,000 U/mL IL-4 (Cellgenix). After 3 and 6 days, half of the medium was replaced by fresh medium containing cytokines. To induce DC maturation, 1,000 U/mL TNF $\alpha$ (Cellgenix), GM-CSF and IL-4 were added on day 6, and cultures were continued for 3 days. Monocyte purity was determined by flow cytometry, using CD45-FITC (BD Biosciences, Heidelberg, Germany) and CD14-PE

Table 1. Patients characteristics.

\begin{tabular}{|c|c|c|}
\hline & Dendritic cell culture & Treg frequency \\
\hline Number and gender & 9 (9 male, 0 female) & 13 (11 male, 2 female) \\
\hline Mean age (range) & 63.1 yrs $(47-72)$ & 58.8 yrs $(47-73)$ \\
\hline \multirow[t]{4}{*}{ Tumor site: } & 2 & 3 \\
\hline & 3 & 6 \\
\hline & 3 & 4 \\
\hline & 1 & 0 \\
\hline \multirow[t]{4}{*}{ Tumor stage: } & 1 & 1 \\
\hline & 1 & 2 \\
\hline & 4 & 3 \\
\hline & 3 & 6 \\
\hline Recurrent disease & 0 & 2 \\
\hline Surgical treatment & 2 & 3 \\
\hline
\end{tabular}


(Beckman-Coulter, Krefeld, Germany) monoclonal antibodies. To monitor DC differentiation and maturation, the frequencies of $\mathrm{CD} 14^{+} \mathrm{CD} 83^{\text {neg }}$ monocytes, CD14 ${ }^{\text {neg }}$ CD $83^{\text {neg }}$ immature $D C$ and CD14 ${ }^{\text {neg }}$ CD $83+$ mature DC were determined by flow cytometry using CD14-PE and CD83-FITC (Beckman-Coulter) monoclonal antibodies.

\section{Flow cytometric determination of Treg frequencies}

Venous blood $(1 \mathrm{~mL})$ was collected in heparinized tubes and erythrocyte lysis was performed with $14 \mathrm{~mL}$ ammonium chloride solution $(\mathrm{NH} 4 \mathrm{Cl})$ for $10 \mathrm{~min}$ at $4^{\circ} \mathrm{C}$. After washing cells twice with PBS, cells were permeabilized with $1 \mathrm{~mL}$ Cytofix solution (BD Biosciences) for $15 \mathrm{~min}$ at $4^{\circ} \mathrm{C}$, washed twice with Permwash solution (BD Biosciences) and stained in Permwash solution with CD25-PECy5, CD4-PECy7, CD8-APC (all BD Biosciences) and FOXP3-FITC (eBioscience, Frankfurt, Germany) monoclonal antibodies for $20 \mathrm{~min}$ at $4^{\circ} \mathrm{C}$. Finally, cells were washed in $4 \mathrm{~mL}$ PBS and fixed with $100 \mu \mathrm{L} \mathrm{4 \%}$ para-formaldehyde (EMS, Hatfield, PA) prior to analysis on a FACS Canto flow cytometer using DIVA software (BD Biosciences). Treg were identified as $\mathrm{CD}^{+} \mathrm{CD} 25^{\text {high- }}$ $\mathrm{FOXP}^{+}$lymphocytes by sequential gating (Fig. 1), and frequencies of Treg are shown as percent $(\%)$ of $\mathrm{CD}^{+}{ }^{+}$lymphocytes. Absolute numbers were calculated from frequencies and cell counts determined on a blood cell analyzer.

\section{Statistical analysis}

Data are presented as geometric means \pm standard error of means, and statistical significance was evaluated using the Student's t-test.

\section{RESULTS}

\section{Frequency of regulatory $T$ cells}

The frequency of Treg in HNSCC patients prior and after radio-chemotherapy as well as in the control group was determined by flow cytometry. Treg were identified as $\mathrm{CD}^{+}{ }^{+} \mathrm{CD} 25^{\text {high }} \mathrm{FoxP}^{+}$cells within the lymphocyte population (Fig. 1). The mean frequency of $\mathrm{CD} 4{ }^{+} \mathrm{CD} 25^{\text {high }} \mathrm{FOXP} 3{ }^{+}$Treg measured by flow cytometry ( $\mathrm{n}=13$ ) was significantly increased $(\mathrm{p}=$ $0.001)$ in HNSCC patients prior to RCT $(0.33 \pm 0.6 \%)$ compared to healthy controls $(0.11 \pm 0.2 \%)$. RCT had diverse effects with an average Treg frequency of 0.36 $\pm 0.09 \%$ after RCT (Fig. 2). Seven patients showed an average increase of $+0.28 \pm 0.1 \%$ in Treg frequency after RCT while the other six patients showed an average decrease of $-0.21 \pm 0.1 \%$.

The frequency of Treg was further determined in subgroups of patients according to their chemotherapy protocol. Whether patients were treated with cisplatin $(\mathrm{n}=3), 5$-fluorouracil and cisplatin \pm cetuximab $(n=4)$, or mitomycin $C$ and cisplatin $(n=6)$, no uniform alteration of Treg frequencies was observed in any of these subgroups (Fig. 3). We also determined the absolute numbers of lymphocytes, Treg and CD $4^{+}$ $\mathrm{T}$ cells before and after RCT as significant variations in HNSCC patients have been reported [19]. In HNSCC patients, the absolute number of Treg decreased from $11.6 \pm 3 / \mu \mathrm{L}$ before RCT to $7.1 \pm 3 / \mu \mathrm{L}$ after
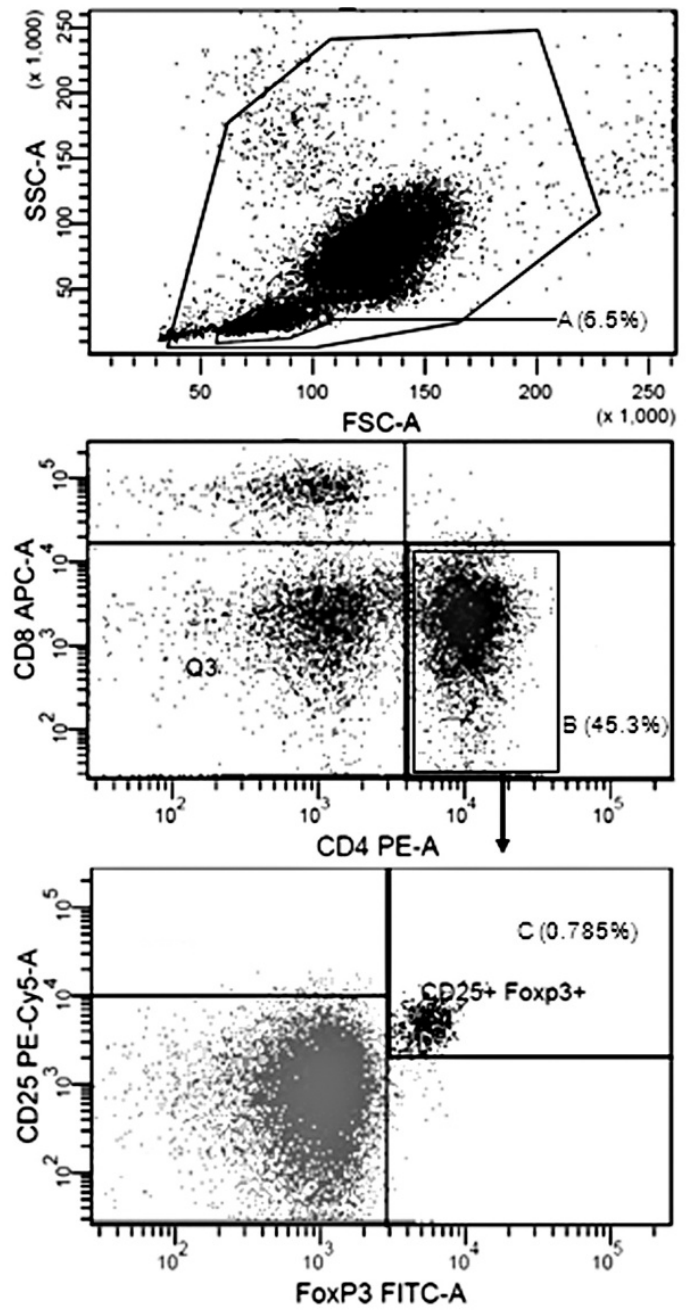

Fig. 1. Strategy for flow cytometric determination of Treg frequencies. Treg frequencies in peripheral blood of patients and controls were determined by flow cytometry. Lymphocytes (A) were identified based on their forward (FSC) and side scatter characteristic (SSC). Within the lymphocyte population, $\mathrm{CD} 4{ }^{+} \mathrm{CD} 8$ neg cells were gated (B) and the subpopulation of $\mathrm{CD}_{2} 5^{\text {high }} \mathrm{FOXP}^{+}$cells quantitated in a dotplot showing CD25 versus FOXP3 expression (C).

RCT. Correspondingly, the absolute number of $\mathrm{CD}^{+}$ $\mathrm{T}$ cells in HNSCC patients decreased from 3,437 \pm $364 / \mu \mathrm{L}$ before RCT to $1,960 \pm 367 / \mu \mathrm{L}$ after RCT. The mean number of leukocytes measured by whole blood count was $8,800 \pm 0.7 / \mu \mathrm{L}$ before RCT and $5,600 \pm 0.6 / \mu \mathrm{L}$ after RCT.

\section{Dendritic cell generation}

To analyze the functionality of monocytes in HNSCC patients, peripheral blood monocytes were differentiated into immature DC in the presence of GM-CSF and IL-4 before maturation was induced by the addition of TNF $\alpha$. Differentiation and maturation were monitored by determining the expression of the monocyte marker CD14 and the marker for mature DC, CD83, on the cell surface [20]. Immunomagnetic monocyte enrichment $(\mathrm{n}=9)$ resulted in a high purity of $\mathrm{CD}^{+} 4^{+}$cells $(85.3 \pm 3.2 \%)$. After six days of monocyte culture with GM-CSF and IL-4, cells 


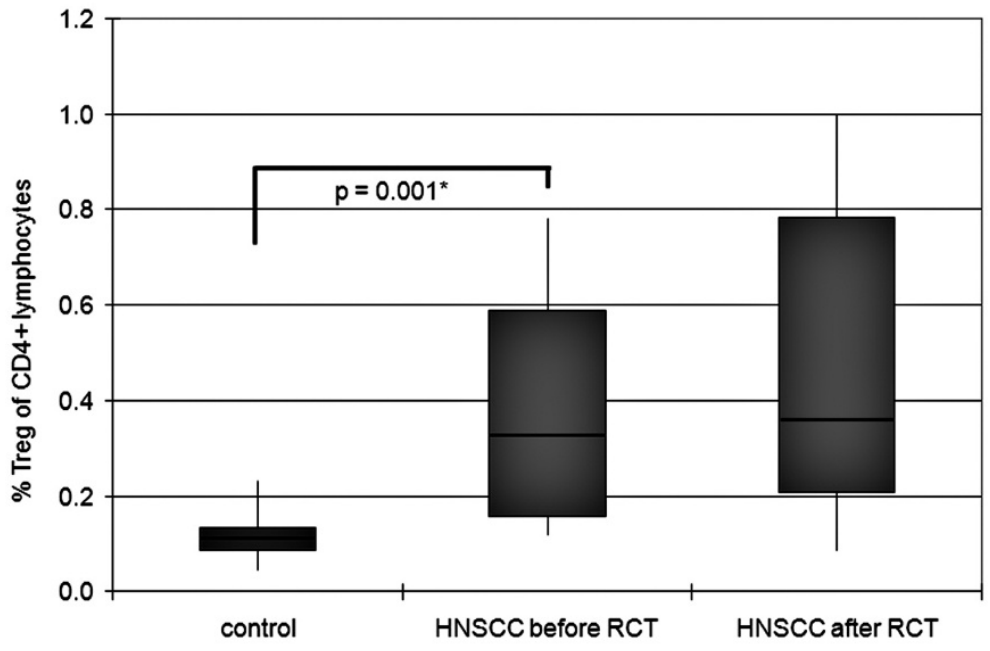

Fig. 2. Treg frequencies in peripheral blood of HNSCC patients. Treg frequencies of HNSCC patients before and after RCT $(n=13)$ or from healthy individuals $(\mathrm{n}=10)$ were determined as illustrated in Figure 1. Results are shown as percentages of $\mathrm{CD}^{+}{ }^{+} \mathrm{CD} 25^{\text {high }} \mathrm{FOXP} 3^{+}$Treg of $\mathrm{CD} 4^{+}$lymphocytes and displayed in quartiles of $0,25,75$ and 100 . Horizontal bars indicate geometric mean values.

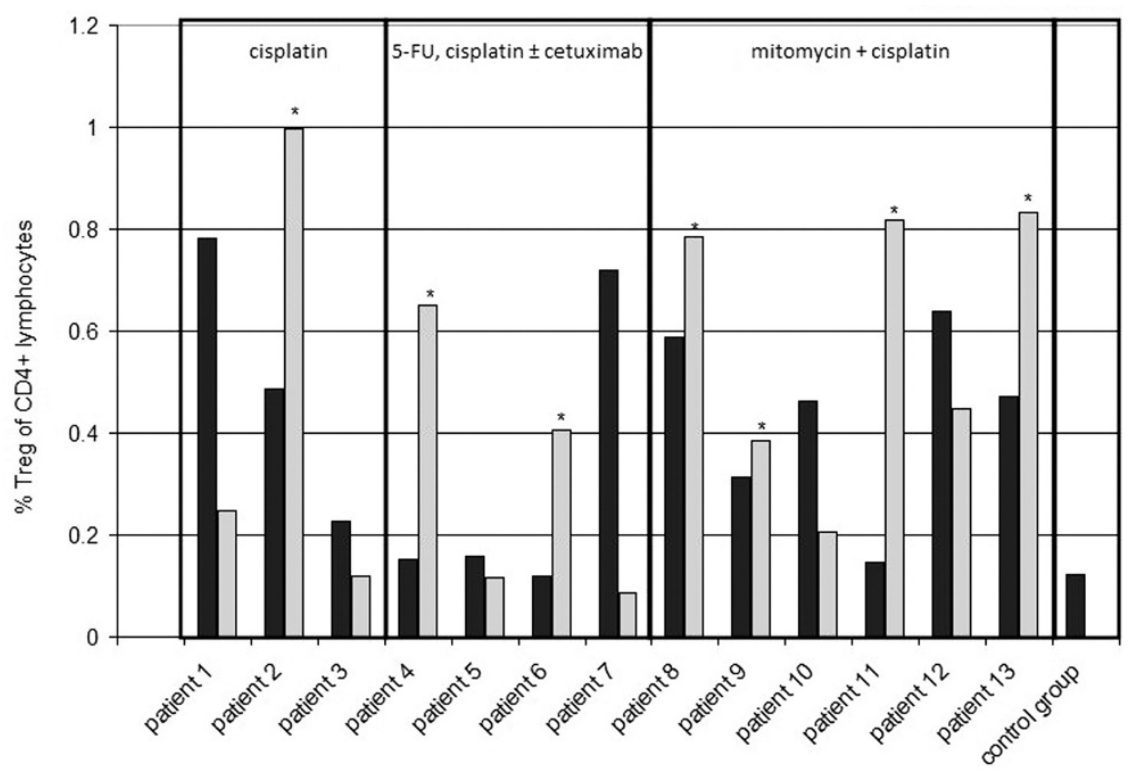

Fig. 3. The frequency of Treg before and after radio-chemotherapy in individual HNSCC patients. Treg frequencies before (black bars) and after radio-chemotherapy (grey bars) of individual patients receiving three different RCT regimens were determined. The mean frequency of Treg in the control group is shown in the last column. Patients showing an increase in Treg frequency after RCT are indicated $(*)$.

\section{Day 0}

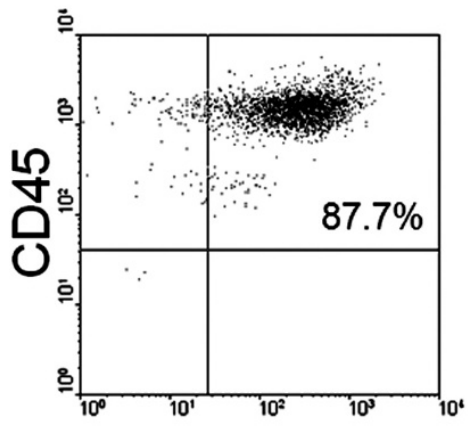

Day 6

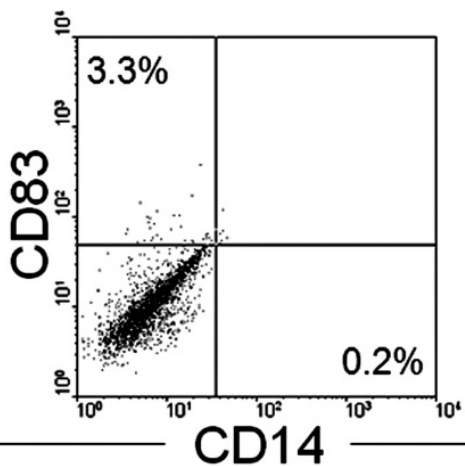

Day 9

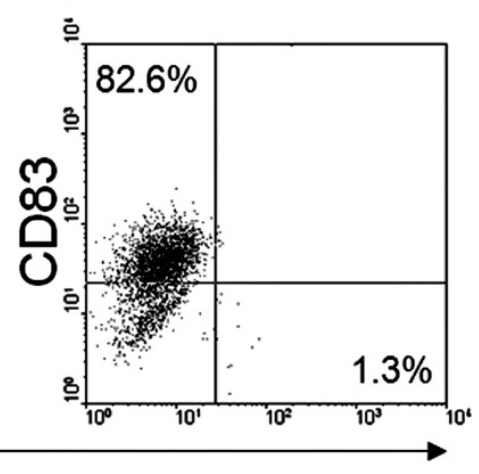

Fig. 4. Successive generation of immature and mature dendritic cells from monocytes. Monocytes (day 0) were cultured for 6 days in the presence of GM-CSF and IL-4 to induce DC differentiation, followed by a three day culture period in the presence of GM-CSF, IL-4 and TNF $\alpha$ to induce DC maturation. Monocyte purity was determined by CD45/CD14 staining (day 0). The

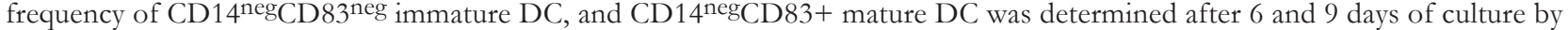
flow cytometry. Quadrants were set according to isotype controls.

showed a loss of CD14 marker (16.3 $\pm 9.0 \%)$. CD83 expression, was detectable only on a small fraction of cells $(1.5 \pm 0.4 \%)$, which confirms that the cultured monocytes had acquired the CD14 ${ }^{\text {neg }}$ CD 83 $3^{\text {neg }}$ phenotype of immature DC (Fig. 4).
Following maturation of the cells with TNF $\alpha$, CD14 expression was almost absent $(0.8 \pm 0.2 \%)$, whereas CD83 was up-regulated (38.8 $\pm 10.6 \%$ CD83+ cells), indicating maturation of DC. However, the ability of DC to mature in HNSCC patients $(n=6)$ 


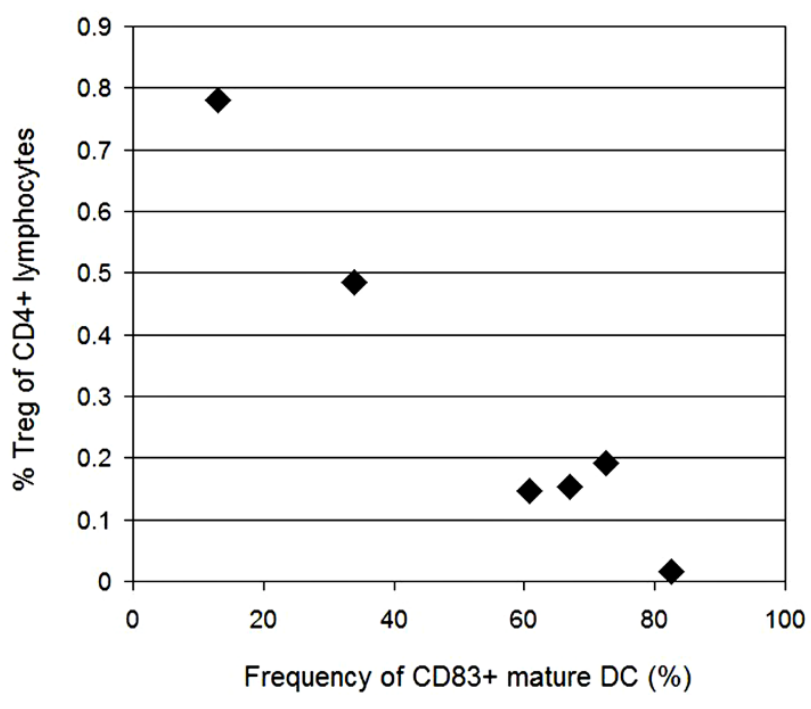

Fig. 5. Association of DC maturation and Treg frequency in the peripheral blood of HNSCC patients. The frequency of mature DC (CD14 $\left.{ }^{\text {neg }} \mathrm{CD} 83+\right)$ after 9 days of differentiation and maturation culture is plotted against the frequency of $\mathrm{CD}^{+}{ }^{+} \mathrm{CD} 25^{\text {high }} \mathrm{FOXP} 3{ }^{+}$Treg in the blood of HNSCC $\mathrm{pa}-$ tients prior to RCT $(n=6)$. Treg frequencies are shown as percent $(\%)$ of $\mathrm{CD}^{+}{ }^{+}$lymphocytes.

appeared to negatively correlate with the frequency of $\mathrm{CD}^{+}{ }^{+} \mathrm{CD} 25^{\text {highFOXP3 }}{ }^{+}$Treg before RCT, with a trend towards significance (Fig. 5). Patients with a Treg frequency below $0.4 \%$ of $\mathrm{CD}^{+}{ }^{+} \mathrm{T}$ cells in the peripheral blood showed an increased ability of DC maturation measured by CD83 expression (70.3 \pm 5.5\%) compared to patients with a Treg frequency above $0.4 \%$ of $\mathrm{CD}^{+} \mathrm{T}$ cells, in which cells maintained an immature phenotype. (20.8 $\pm 10.5 \%$ CD $83+$ cells $)$.

\section{Discussion}

Tumor induced immunosuppression is a well known phenomenon in cancer patients, for which changes in the Treg compartment may play a central role [21]. In the present study, it was documented, that the frequency of $\mathrm{CD}^{+}{ }^{+} \mathrm{CD} 25^{\text {high }} \mathrm{FOXP} 3^{+}$Treg in peripheral blood of HNSCC patients was significantly increased compared to healthy controls, suggesting an active mechanism of tumor-induced immune escape. This finding is in accordance with a previous study in HNSCC [16] and similar changes have also been reported for other types of cancer [12].

RCT has been reported to preferentially deplete $\mathrm{CD}^{+} \mathrm{T}$ cells in HNSCC patients [19]. Analyzing the effects of RCT on the Treg population, we observed that in $7 / 13$ patients Treg frequencies within $\mathrm{CD}^{+} \mathrm{T}$ cells increased, whereas $6 / 13$ patients showed a decrease in Treg frequencies after RCT. Presumably, not all chemotherapeutic agents have the same effect on Treg frequency, and $\mathrm{T}$ cell subsets may be affected differently by RCT [22]. Studies with a higher number of patients receiving the same drug regimen could provide a more definite result. Of note, a lack of a distinct phenotypic marker for human Treg makes comparison of data obtained by different investigators difficult. Most commonly, Treg are defined as $\mathrm{CD} 4^{+} \mathrm{CD} 25^{\text {high }} \mathrm{FOXP} 3^{+}$, but also the presence of CD39, and the absence of CD127 and CD49d have been used to define Treg [23].

The results presented here suggest that there might be an association between the Treg frequency and abnormalities in DC maturation. In HNSCC patients with a high frequency of Treg in peripheral blood, monocytes failed to develop to mature DC ex vivo as evident by the lack of CD83 up-regulation. HNSCC patients with a low frequency of Treg show a normal ability of DC maturation as compared to normal donors who had $65 \pm 6.8 \%$ CD $83+$ cells after TNF $\alpha$ induced DC maturation [18]. Whether such effects are long lasting or whether there is normalization when Treg are depleted, is currently unknown.

The defective DC maturation of monocytes obtained from cancer patients possibly reflects tumor-induced suppression, and TNF $\alpha$ used as the only maturation signal may not be sufficient to overcome this suppression. Several factors that negatively influence DC maturation in vitro are described in the literature including IL-10 and TGFß production by regulatory $\mathrm{T}$ cells [24] or vascular endothelial growth factor produced by human cancer cells [25]. Both mechanisms, a direct effect mediated by tumor cells or a tumor-induced effect mediated by Treg, could cause the decreased DC maturation in HNSCC patients. In another study, high thrombocyte counts in blood samples were found to interfere with DC development [26], but thrombocyte counts were in a normal range in all participants of this study (data not shown). Also, neither the patients' age nor their level of alcohol and nicotine consumption gave an explanation for the deficiency in DC maturation of certain patients (data not shown). Nevertheless, it should be stressed, that monocytes of all patients differentiated normally to immature DC upon culture with GM-CSF and IL-4, thus, only maturation of DC appears to be affected.

Aiming for an increase in survival rates, future therapy of HNSCC patients will likely focus on the combination of surgery, RCT and immunotherapy. In order to determine an optimal and feasible timing of the various therapeutic modalities, the understanding of depletion and recovery of immuno-relevant cell populations is essential. Therefore, longitudinal studies of cell frequencies, including Treg but also myeloid suppressor cells and $\mathrm{T}_{\mathrm{H}^{-17}}$ cells are warranted, all of which may be differently affected by RCT. Having in mind that Treg are highly immunosuppressive, the application of DC-based anticancer vaccination would be most effective when frequencies of Treg are low and those of $\mathrm{CD}^{+}$and $\mathrm{CD} 8+$ lymphocytes are comparatively high. Whether this point of time can be reached before, during or after RCT needs to be determined. It will also be important to identify regimens of RCT that are most effective for elimination of immunosuppressive Treg and functional normalization of DC, as well as subgroups of patients who will especially benefit from a supportive anticancer vaccination therapy. As the combination of RCT and immunotherapy is hypothesized to have an additive effect in cancer patients, this strategy may provide for 
the opportunity to employ RCT in a more concerted manner [27, 28].

Acknowledgement: The authors wish to thank Corinna Peters and Heike Löffler for excellent technical assistance.

\section{REFERENCES}

1. Oddone N, Morgan GJ, Palme CE et al. Metastatic cutaneous squamous cell carcinoma of the head and neck: the immunosuppression, treatment, extranodal spread, and margin status (ITEM) prognostic score to predict outcome and the need to improve survival. Cancer. 2009;115:1883-1891.

2. Nicolette CA, Healey D, Tcherepanova I et al. Dendritic cells for active immunotherapy: optimizing design and manufacture in order to develop commercially and clinically viable products. Vaccine. 2007;25 Suppl 2:B47-B60.

3. O'Neill DW, Adams S, Bhardwaj N. Manipulating dendritic cell biology for the active immunotherapy of cancer. Blood. 2004;104:2235-2246.

4. Whiteside TL, Odoux C. Dendritic cell biology and cancer therapy. Cancer Immunol Immunother. 2004;53:240248.

5. Whiteside TL. Anti-tumor vaccines in head and neck cancer: targeting immune responses to the tumor. Curr Cancer Drug Targets. 2007;7:633-642.

6. Hoffmann TK, Muller-Berghaus J, Ferris RL et al. Alterations in the frequency of dendritic cell subsets in the peripheral circulation of patients with squamous cell carcinomas of the head and neck. Clin Cancer Res. 2002;8:1787-1793.

7. Sorg RV, Ozcan Z, Brefort T et al. Clinical-scale generation of dendritic cells in a closed system. J Immunother. 2003;26:374-383.

8. Higano CS, Schellhammer PF, Small EJ et al. Integrated data from 2 randomized, double-blind, placebo-controlled, phase 3 trials of active cellular immunotherapy with sipuleucel-T in advanced prostate cancer. Cancer. 2009;115:3670-3679.

9. Akdis CA, Akdis M. Mechanisms and treatment of allergic disease in the big picture of regulatory T cells. J Allergy Clin Immunol. 2009;123:735-746.

10. Brown K, Wong W. Diagnostic value of regulatory T cells: a new facet of a much studied cell population. Transplantation. 2008;86:1485-1491.

11. Vandenbark AA, Offner H. Critical evaluation of regulatory $\mathrm{T}$ cells in autoimmunity: are the most potent regulatory specificities being ignored? Immunology. 2008;125:113.

12. Nishikawa H, Sakaguchi S. Regulatory $T$ cells in tumor immunity. Int J Cancer. 2010;127:759-767.

13. Ladoire S, Arnould L, Apetoh L et al. Pathologic complete response to neoadjuvant chemotherapy of breast carcinoma is associated with the disappearance of tumorinfiltrating foxp $3^{+}$regulatory $\mathrm{T}$ cells. Clin Cancer Res. 2008;14:2413-2420.

14. Perez SA, Karamouzis MV, Skarlos DV et al. CD4+ CD25+ regulatory T-cell frequency in HER-2/neu (HER)positive and HER-negative advanced-stage breast cancer patients. Clin Cancer Res. 2007;13:2714-2721.

15. Ghiringhelli F, Menard C, Puig PE et al. Metronomic cyclophosphamide regimen selectively depletes $\mathrm{CD}^{+}$ $\mathrm{CD} 25+$ regulatory $\mathrm{T}$ cells and restores $\mathrm{T}$ and $\mathrm{NK}$ effector functions in end stage cancer patients. Cancer Immunol Immunother. 2007;56:641-648.
16. Strauss L, Bergmann C, Gooding W, Johnson JT, Whiteside TL. The frequency and suppressor function of $\mathrm{CD} 4^{+} \mathrm{CD} 25^{\text {high }}$ Foxp $3^{+} \mathrm{T}$ cells in the circulation of $\mathrm{pa}-$ tients with squamous cell carcinoma of the head and neck. Clin Cancer Res. 2007;13:6301-6311.

17. Zhou LJ, Tedder TF. CD14+ blood monocytes can differentiate into functionally mature CD $83+$ dendritic cells. Proc Natl Acad Sci U S A. 1996;93:2588-2592.

18. Rapp M, Ozcan Z, Steiger HJ et al. Cellular immunity of patients with malignant glioma: prerequisites for dendritic cell vaccination immunotherapy. J Neurosurg. 2006;105: 41-50.

19. Kuss I, Hathaway B, Ferris RL, Gooding W, Whiteside TL. Decreased absolute counts of T lymphocyte subsets and their relation to disease in squamous cell carcinoma of the head and neck. Clin Cancer Res. 2004;10:37553762 .

20. Lechmann M, Berchtold S, Hauber J, Steinkasserer A. CD83 on dendritic cells: more than just a marker for maturation. Trends Immunol. 2002;23:273-275.

21. Whiteside TL. Tricks tumors use to escape from immune control. Oral Oncol. 2009;45:e119-e123.

22. Ersvaer E, Liseth K, Skavland J, Gjertsen BT, Bruserud O. Intensive chemotherapy for acute myeloid leukemia differentially affects circulating TC1, TH1, TH17 and TREG cells. BMC Immunol. 2010;11:38.

23. Kleinewietfeld M, Starke M, Di Mitri D et al. CD49d provides access to "untouched" human Foxp $3^{+}$Treg free of contaminating effector cells. Blood. 2009;113:827-836.

24. Misra N, Bayry J, Lacroix-Desmazes S, Kazatchkine MD, Kaveri SV. Cutting edge: human $\mathrm{CD} 4{ }^{+} \mathrm{CD} 25+\mathrm{T}$ cells restrain the maturation and antigen-presenting function of dendritic cells. J Immunol. 2004;172:4676-4680.

25. Gabrilovich DI, Chen HL, Girgis KR et al. Production of vascular endothelial growth factor by human tumors inhibits the functional maturation of dendritic cells. Nat Med. 1996;2:1096-1103.

26. Kissel K, Berber S, Nockher A et al. Human platelets target dendritic cell differentiation and production of proinflammatory cytokines. Transfusion. 2006;46:818-827.

27. Menard C, Martin F, Apetoh L, Bouyer F, Ghiringhelli F. Cancer chemotherapy: not only a direct cytotoxic effect, but also an adjuvant for antitumor immunity. Cancer Immunol Immunother. 2008;57:1579-1587.

28. Zhang L, Dermawan KT, Jin ML, Xiong SD, Chu YW. Does chemotherapy augment anti-tumor immunotherapy by preferential impairment of regulatory T cells? Med Hypotheses. 2008;71:802-804.

Received: September 7, 2010 / Accepted: September 28, 2010

Address for correspondence:

Patrick J. Schuler, MD

Department of Otorhinolaryngology

University of Duisburg-Essen

Hufelandstr. 55

45147 Essen

Germany

Tel.: $\quad+49-201-723-2481$

Fax: +49-201-723-5903

E-Mail: patrick.schuler@uk-essen.de 